\title{
Journal of

\section{Intramolecular excimer emission as a blue light source in fluorescent organic light emitting diodes: a promising molecular design $\dagger$}

\author{
Damien Thirion, Maxime Romain, Joëlle Rault-Berthelot* and Cyril Poriel*
}

Received 22nd December 2011, Accepted 5th February 2012

DOI: $10.1039 / \mathrm{c} 2 \mathrm{jm} 16774 \mathrm{c}$

\begin{abstract}
Intramolecular excimer emission arising from organic molecules as a blue light source in fluorescent Small Molecule Organic Light Emitting Diodes (SMOLEDs) is almost absent from the literature. In this work, three aryl-substituted DiSpiroFluorene-IndenoFluorenes (DSF-IFs 1-3) possessing different fluorescent properties due to their different main emitters have been investigated through a structure-property relationship study. Due to its particular geometry, the rigid DSF-IF platform 2 allows an 'aryl/fluorene/aryl' dimer to be preformed in the ground state leading, in the excited state, to a deep blue fluorescent emission through strong $\pi-\pi$ intramolecular interactions between the two 'aryl/ fluorene/aryl' arms. 2 has been successfully used as an emitting layer in a SMOLED with electroluminescence arising from electrogenerated intramolecular excimers and the properties of these excimer-based OLEDs have been compared to those of two model compounds (1 and $\mathbf{3})$. The simple and non-optimized double-layer device displays a deep blue colour (CIE coordinates: $0.19 ; 0.18$ ) exhibiting a luminance of $510 \mathrm{Cd} \mathrm{m}^{-2}$ with a luminous efficiency of $c a .0 .1 \mathrm{Cd} \mathrm{A}^{-1}$. This work is, to the best of our knowledge, the first rational and comparative study describing an intramolecular excimer based-SMOLED.
\end{abstract}

\section{Introduction}

Intermolecular $\pi-\pi$ interactions play a key role in the field of Materials Science and especially in Organic Electronics. Indeed, in an Organic Field Effect Transistor (OFET), intermolecular $\pi-\pi$ interactions between molecules in the thin solid film must be very strong to ensure high mobility of charge carriers. ${ }^{1-4}$ Conversely, in an Organic Light Emitting Diode (OLED), intermolecular $\pi-\pi$ interactions should be usually suppressed to avoid any parasite and uncontrolled emission colour due to intermolecular excimer formation (dimer in the excited state). However, in white OLEDs the use of a single fluorescent emitter which can form an excimer through intermolecular $\pi-\pi$ interactions has been designed in order to cover the whole visible range from 400 to $700 \mathrm{~nm} .^{5-7}$ Thus, due to their importance in OLED technology, intermolecular $\pi-\pi$ interactions have been hence extensively studied for the last twenty years, but intramolecular $\pi-\pi$ interactions have not been deeply investigated. Indeed, if one can control the formation of intramolecular $\pi-\pi$ interactions within a fluorescent dye and in the meantime avoid intermolecular $\pi-\pi$ interactions, then intramolecular excimer

Université de Rennes 1-UMR CNRS 6226 "Sciences Chimiques de Rennes", Campus de Beaulieu, 35042 Rennes Cedex, France. E-mail: Cyril.poriel@univ-rennes1.fr; Joelle.rault-berthelot@univ-rennes1.fr

$\uparrow$ Electronic supplementary information (ESI) available: Some SMOLED characterizations for 1-3, copy of ${ }^{1} \mathrm{H}$ and ${ }^{13} \mathrm{C}$ NMR spectra and $\mathrm{CV}$ of 3, CIE coordinates of the different OLEDs. See DOI: $10.1039 / \mathrm{c} 2 \mathrm{jm} 16774 \mathrm{c}$ emission could be used as a light source in an OLED. Indeed, the strategy to generate blue light (and light in general) in an OLED is most of the time always the same and consists of designing a fluorophore with emission properties directly arising from its $\pi$-conjugated backbone modulated (or not) by the electronic effects of different substituents (for example, donor-acceptor $\pi$-conjugated dyes). ${ }^{8-12}$ In this work, we wish to report a unique and promising strategy to generate light in an OLED, that is using intramolecular excimer emission. Recently, our group has designed an original family of aryl-substituted DiSpiroFluoreneIndenoFluorene (DSF-IF) derivatives, which possess two "arylfluorene-aryl" moieties in a rigid face-to-face arrangement. This particular face-to-face geometry predominantly leads for these ' $3 \pi-2$ spiro' $\$$ compounds $^{13}$ to conformationally controllable intramolecular excimer fluorescence emission. ${ }^{14-16}$ However, these systems have been mainly studied in solution and never incorporated in an optoelectronic device. In the present work, we wish to report preliminary results on intramolecular excimer emission as a deep blue light source in an OLED. Three structurally related DSF-IFs 1-3 (Scheme 1) possessing different emission properties have been investigated through a structureproperty relationship study. Their optical properties have first been investigated in detail before successfully incorporating them as an emitting layer (EML) in blue SMOLEDs. The performances and electro-optic properties have been discussed. If the

\$ ' $3 \pi$-2 spiro' is a geometric concept meaning three $\pi$-conjugated systems linked by two spiro bridges. See ref. 13. 


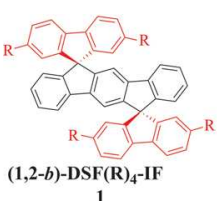

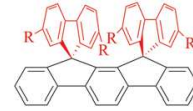

$(2,1-a)-\mathrm{DSF}(\mathrm{R})_{4}-\mathrm{IF}$

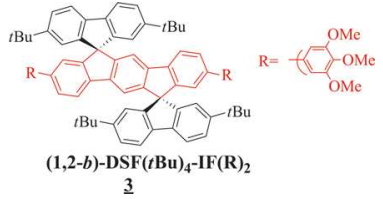

Scheme 1 Molecules investigated in this work.

use of intermolecular excimer emission as a light source in a SMOLED is known for organic ${ }^{5-7}$ and organometallic compounds, ${ }^{17-20}$ the use of intramolecular excimer emission arising from pure organic molecules has been reported, to the best of our knowledge, only once. ${ }^{16}$ In the light of the marked difference observed between the excimer-based SMOLEDs (with $\mathbf{2}$ as EML) and the "classical" SMOLEDs (with $\mathbf{1}$ or $\mathbf{3}$ as EML), we are convinced that this strategy may open new avenues in the design of efficient blue fluorophores for optoelectronic applications.

\section{Results and discussion}

The molecular design adopted is the following: the (2,1-a)-DSFIF platform found in $\mathbf{2}$ has been chosen in order to impose a rigid arrangement of the two cofacial "aryl/fluorene/aryl" arms and to allow these arms to interact with one another in the ground state. This will then favour the facile and easily controllable formation of excimers in the excited state. In addition, the 3D geometry of 2 should suppress the non-desired intermolecular $\pi-\pi$ interactions in thin film leading to a stable blue colour only arising from intramolecular $\pi-\pi$ interactions. Two other molecules (1 and 3), with a very similar molecular structure but with 'classical' fluorescence properties arising from their $\pi$-conjugated backbone (without any excimer emission), will be also investigated, for comparison purpose, in order to evaluate the efficiency of using intramolecular excimer emission in an OLED. The molecule 1, a regioisomer of $\mathbf{2}$, presents a $(1,2-b)$-DSF-IF core and two "3,4,5-trimethoxyphenyl/fluorene/3,4,5-trimethoxyphenyl" arms but the latter do not interact with one another (as it is the case in 2). The molecule 3 is also constituted of a $(1,2-b)$-DSF-IF core, but this time the indenofluorenyl unit is substituted by two 3,4,5-trimethoxyphenyl moieties.

\section{Synthesis}

The synthesis of $\mathbf{1}$ and $\mathbf{2}$ has been previously reported. ${ }^{21} \mathbf{3}$ has been synthesized through a Pd-catalyzed Suzuki-Miyaura crosscoupling reaction between the related dibromo-indenofluorene substituted compound (1,2-b)-DSF $(t-\mathrm{Bu})_{4}-\mathrm{IF}(\mathrm{Br})_{2}$ ref. 12 and 3,4,5-trimethoxyphenylboronic acid using $\mathrm{Pd}_{2}(\mathrm{dba})_{3} / \mathrm{P}(t-\mathrm{Bu})_{3}$ as the catalytic system, potassium carbonate as the base in a mixture of toluene and water at $100{ }^{\circ} \mathrm{C}$ (yield: $55 \%$, Scheme 2).
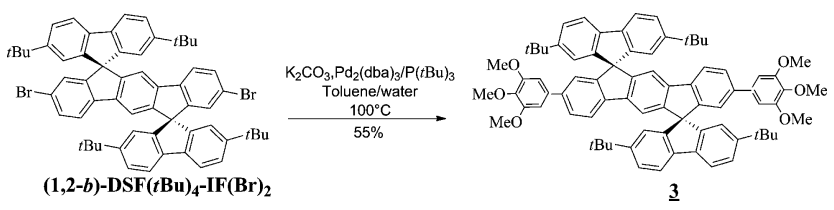

Scheme 2 Synthesis of 3.

\section{Optical properties}

The absorption spectrum of $\mathbf{1}$, in solution in THF (Fig. 1A), is quite well defined with one shoulder at $301 \mathrm{~nm}$ and four maxima at $\lambda=314,331,337,345 \mathrm{~nm} \cdot{ }^{14}$ As previously reported, the three first main bands have been ascribed to the "aryl-fluorene-aryl" moieties as these bands are also found in other spirolinked oligoaryl derivatives. ${ }^{22-24}$ The band at $345 \mathrm{~nm}$ has been assigned to the $\pi-\pi^{*}$ electronic transition of the $(1,2-b)$-indenofluorenyl core in perfect accordance with that of its non-substituted (without aryl rings) congener $(1,2-b)$-DSF-IF $\left(\lambda_{\max }=345 \mathrm{~nm}\right){ }^{25,26} \mathrm{It}$ should be stressed that this band is red-shifted by $11 \mathrm{~nm}$ compared to that of (1,2-b)-indenofluorene $\left((1,2-b)-\mathrm{IF}, \lambda_{\max }=\right.$ $334 \mathrm{~nm})$, due to the electronic effects of the two spirolinked diarylfluorene units. ${ }^{25-27}$ The absorption spectrum of $\mathbf{2}$, in solution in THF (Fig. 1B), is less defined compared to that of 1 with nevertheless one shoulder at $314 \mathrm{~nm}$ and two maxima at 328 and $340 \mathrm{~nm}$. As mentioned above, the bands at 314 and $328 \mathrm{~nm}$ have been ascribed to the "aryl-fluorene-aryl" moieties. The transition recorded at $340 \mathrm{~nm}$ has been assigned to the (2,1- $a$ )-indenofluorenyl core in accordance with that of its non-substituted congener $(2,1-a)$-DSF-IF $\left(\lambda_{\max }=339 \mathrm{~nm}\right) .{ }^{25}$ The slight blue-shift observed between the maxima of $\mathbf{2}\left(\lambda_{\max }=340 \mathrm{~nm}\right)$ and $\mathbf{1}\left(\lambda_{\max }=\right.$ $345 \mathrm{~nm}$ ) has been assigned to a better delocalization of $\pi$-electrons in $\mathbf{1}$ compared to $\mathbf{2}$ due to the different indenofluorenyl cores $(1,2-b$ vs. $2,1-a){ }^{14,25}$ In addition, a red shift of $18 \mathrm{~nm}$ is detected between the maximum of 2 and that of (2,1-a)-indenofluorene $\left((2,1-a)-\mathrm{IF}, \lambda_{\max }=322 \mathrm{~nm}\right)$, due to the electronic effects of the two spirolinked diarylfluorene units. The electronic influence on the indenofluorenyl core of a cofacial diaryl-fluorene $\pi$-dimer found in $\mathbf{2}$, leading to a $18 \mathrm{~nm}$ red shift, is different from that of two non-directly interacting diaryl-fluorene units as found in 1 (red shift: $11 \mathrm{~nm}$, vide supra). Such a difference was also observed in the (2,1-a)-IF/(2,1-a)-DSF-IF (red shift: $17 \mathrm{~nm}$ ) and $(1,2-b)-\mathrm{IF} /(1,2-b)$-DSF-IF (red shift: $11 \mathrm{~nm}$ ) series. Thus, isomers $\mathbf{1}$ and $\mathbf{2}$ present absorption properties governed by both their indenofluorenyl and their "aryl-fluorene-aryl" moieties.

DSF-IF 3 displays a different behaviour due to its different substitution pattern compared to $\mathbf{1}$ and $\mathbf{2}$. Indeed, $\mathbf{3}$ possesses a $(1,2-b)$-indenofluorenyl core substituted by two 3,4,5-trimethoxyphenyl moieties. Thus, the optical properties of $\mathbf{3}$ should be almost fully governed by the "aryl/indenofluorene/aryl" moiety. Indeed, 3 presents an absorption spectrum with a maximum recorded at $362 \mathrm{~nm}$, red shifted by $17 \mathrm{~nm}$ compared to 1 due to the extension of the conjugation length of the 2,6-diaryl-(1,2-b)indenofluorenyl core. This wavelength $(362 \mathrm{~nm})$ has been assigned to a $\pi-\pi^{*}$ transition of the "aryl/indenofluorene/aryl" moiety as it fits well with the maximum reported for a structurally related compound, that is 2,6-diphenylindenofluorene $\left(\lambda_{\max }=350 \mathrm{~nm} \text { in DMF }\right)^{28}$ with nevertheless a $12 \mathrm{~nm}$ red shift caused by the electron donating behaviour of the six methoxy groups borne by $3 .^{24,29,30}$

In thin film, 1-3 display the same behaviour that is a broader absorption spectrum and a slight red shift, usually assigned to the different environment surrounding the molecules (solid vs. liquid) and hence the different dielectric constants. ${ }^{22,31}$

The fluorescence spectrum of $\mathbf{1}$, in solution in THF (Fig. 2A), which mainly arises from its "aryl/fluorene/aryl" moieties, presents two maxima at 381 and $393 \mathrm{~nm}^{14}$ These maxima are red 

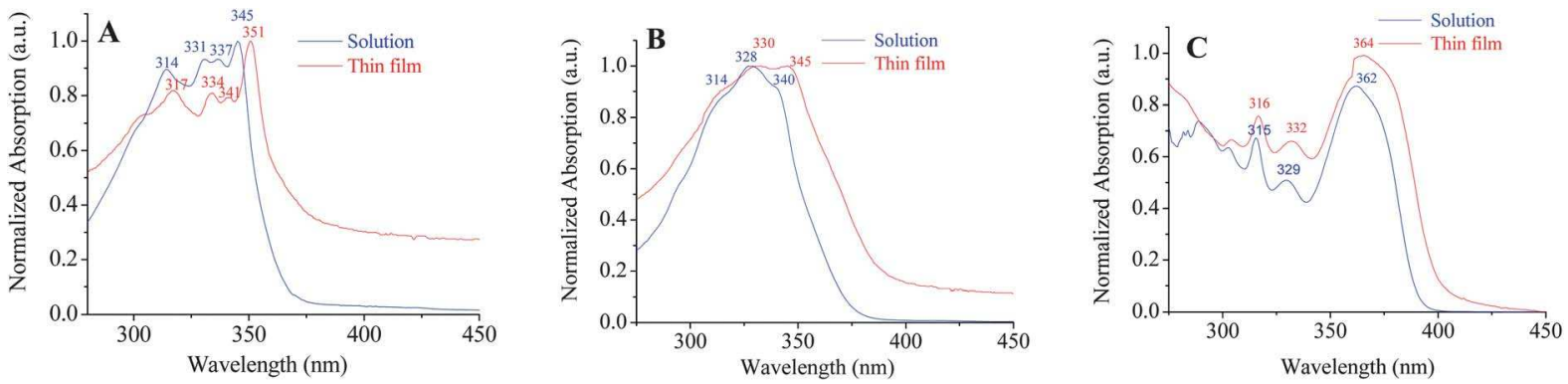

Fig. 1 Absorption spectra of 1 (A), 2 (B) and 3 (C) in solution (blue line, THF, $C=10^{-6} \mathrm{M}$ ) and in thin-solid films (red line), depositing solvent: 1,2dichlorobenzene, $C=15 \mathrm{mg} \mathrm{mL}^{-1}\left(\mathbf{1}\right.$ and 2); THF; $C=10 \mathrm{mg} \mathrm{mL}^{-1}(\mathbf{3})$.
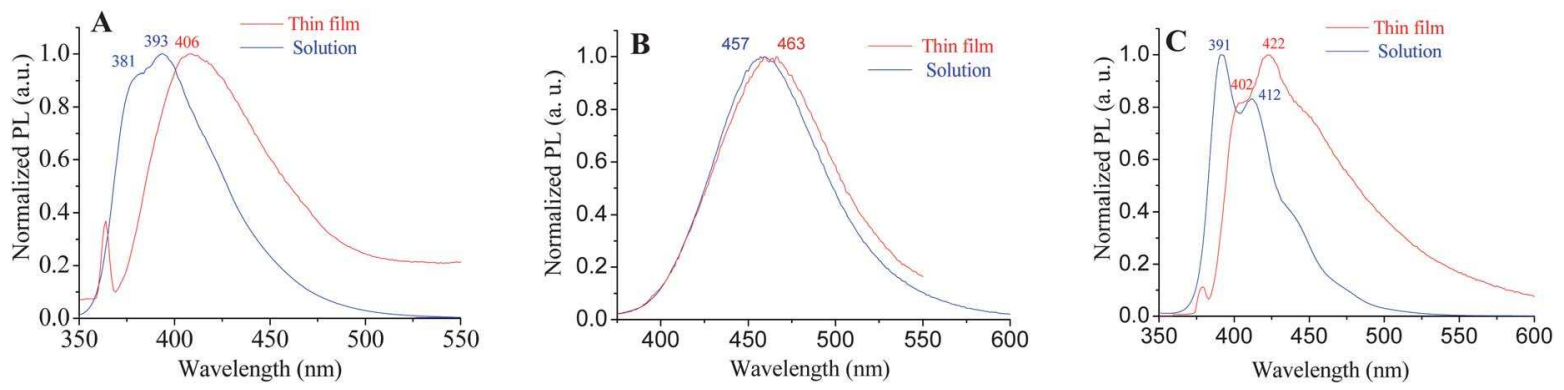

Fig. 2 Emission spectra of (A): 1, (B): 2 and (C): 3, $\lambda_{\mathrm{exc}}=340 \mathrm{~nm}$ (1 and 2), $\lambda_{\mathrm{exc}}=336 \mathrm{~nm}$ (3) in solution (THF 10 $0^{-6}$, blue line) and in thin-solid films (red line); depositing solvent: 1,2-dichlorobenzene, $C=15 \mathrm{mg} \mathrm{mL}^{-1}$ (1 and 2); THF; $C=10 \mathrm{mg} \mathrm{mL}^{-1}$ (3).

shifted compared to those of $2,2^{\prime}, 7,7^{\prime}$-tetraphenyl-9, $9^{\prime}$-spirobifluorene $(\lambda=359,378 \mathrm{~nm})$, which can be considered as two spirolinked "phenyl/fluorene/phenyl" units. ${ }^{22}$ This red shift, ascribed to the electron-donating effect of the methoxy groups (vide supra), ${ }^{24,29,30}$ allows a fine tuning of the emission colour of $\mathbf{1}$. Compound 2 displays a drastically different fluorescent spectrum constituted of a single, large, structureless and red-shifted band (with respect to 1) with a maximum recorded at $457 \mathrm{~nm}$ (Fig. 2B). This behaviour highlights the remarkable effect of the cofacial fluorenes arrangement found in $\mathbf{2}$ and has been ascribed to the emission of intramolecular excimers, due to the interactions between "aryl-fluorene-aryl" moieties in the excited state. ${ }^{14}$ Several groups have also reported similar behaviour for various molecular systems with $\pi-\pi$ interactions. ${ }^{32-40}$ An important feature in the fluorescent spectrum of $\mathbf{2}$ is related to the large Stokes shift i.e. $116 \mathrm{~nm}$ which leads to an emission in the deep blue region. This feature is of key importance as no selfabsorption may hence occur in this blue emitter. The wellresolved emission spectrum of 3 (Fig. 2C, $\lambda_{\max }=391 / 412 \mathrm{~nm}$ ) compared to its absorption spectrum (Fig. 1C) suggests a more rigid/planar structure of $\mathbf{3}$ in the excited state since the bonds joining the indenofluorene unit and the aryl rings acquire some double bond characters. ${ }^{16,41,42}$ Indeed, for species that comprise torsional degrees of freedom in their $\pi$-conjugated core, varying degrees of deviation from the classical mirror image behaviour can be detected. Such differences between absorption and emission bandshapes may be related to the flexible character of the molecules, as already studied for $p$-terphenyl and indenofluorene

$\S$ It should be noted that the fluorescence spectra of $\mathbf{2}$ are independent of the concentration $\left(10^{-7}\right.$ to $\left.10^{-3} \mathrm{M}\right)$. derivatives by ab initio quantum chemical methods. ${ }^{43}$ Compared to 1 , there is a red shift of the two main maxima ( 11 and $19 \mathrm{~nm}$ ) for 3 due to the extension of the conjugation length from diarylfluorene in $\mathbf{1}$ to diaryl-indenofluorene units in $\mathbf{3}$. However and despite this extension of the conjugation length, the emission maxima of $3\left(\lambda_{\max }=391 / 412 \mathrm{~nm}\right)$ are remarkably blue-shifted compared to that of $2\left(\lambda_{\max }=457 \mathrm{~nm}\right.$, vide infra $)$. This feature highlights the efficiency of the molecular design found in $\mathbf{2}$, which allows reaching a deep blue emission with relatively short $\pi$ conjugated molecular fragments (i.e. "aryl/fluorene/aryl"), whereas this deep blue emission wavelength is almost impossible to reach with structurally related 'aryl-fluorene-aryl' derivatives. ${ }^{24}$ For example, in the series of comparable spiro-'arylfluorene-aryl' compounds, described by Salbeck and co-workers, possessing two, four, six, or eight phenyl units connected to the fluorene core, the fluorescence maxima in solution only gradually increase in the order $359,385,395$, and $402 \mathrm{~nm} .{ }^{24}$ Thus, reaching an emission wavelength of $460 \mathrm{~nm}$, as it is the case for 2 , seems to be almost impossible (even with the introduction of appropriate electron-donor substituents) as a limiting value for long chains exists. ${ }^{24}$ Indeed, even bridged-polyphenylene derivatives such as polyfluorene, polyindenofluorene or polypentaphenylene derivatives, known to possess high wavelengths in the blue region, only present an emission maximum at around $420,430 \mathrm{~nm}$ and $445 \mathrm{~nm}$ respectively. ${ }^{44}$ The use of intramolecular excimers emission resulting from 'aryl-fluorene-aryl' fragments to obtain deep blue fluorescent emission appears hence as a possible solution to this issue.

In thin-solid film, $\mathbf{1}$ and $\mathbf{3}$ present a broader and red-shifted spectrum compared to their solution ones due to the different dielectric constants of the environments (liquid vs. solid) as 
discussed above. However, such behaviour can also translate some $\pi-\pi$ intermolecular interactions which can further disturb the purity of the colour. We also noted a marked difference between solution and thin-film fluorescence spectra of $\mathbf{3}$ in the relative intensity of the emission bands, with the second fluorescence band at $422 \mathrm{~nm}$ being more intense compared to the first at $402 \mathrm{~nm}$ (Fig. 2C). This might be ascribed to self-absorption phenomena due to the overlap of the $0-0$ transition emission band and the absorption band which lead to a relative decrease of the intensity of the $0-0$ transition. ${ }^{45}$ However, the shift observed for $\mathbf{3}$ is without any comparison with that described in the case of the previously described 2,6-diphenylindenofluorene for which the thin-film emission is detected at $c a$. $500-530 \mathrm{~nm}$ clearly signing a stacking of the molecules in the solid state due to strong intermolecular $\pi-\pi$ interactions. ${ }^{28}$ Thus, the absence of strong $\pi-\pi$ interactions in the case of $\mathbf{3}$ is hence due to the presence of the two spiro( $t$-Bu-fluorene) units on each side of the indenofluorene core and highlights the efficiency of the present molecular design to avoid any intermolecular $\pi-\pi$ interaction. ${ }^{12}$

Interestingly, the fluorescence spectrum of $\mathbf{2}$ in solution is almost identical to that in the solid state (Fig. 2B) with only a slight red shift of around $6 \mathrm{~nm}$. Thus, the intramolecular "arylfluorene-aryl" dimer formed in the excited state seems to lead to a stable deep blue fluorescence emission even in the solid state. This feature shows that no intermolecular $\pi-\pi$-interactions occur in the thin-film between the molecules of $\mathbf{2}$, due to the steric protection induced by the geometry of the molecule. The molecular design of $\mathbf{2}$ allows hence gathering in a single molecule, a wide HOMO/LUMO gap (ca. $3.4 \mathrm{eV}$, Table 1) and its associated properties (high stability toward oxidation for example) and a deep blue emission in the solid state. Finally, the quantum yield of 1-3 has been evaluated. 1 possesses a high quantum yield, $c a$. $75 \%$ relative to quinine sulfate, as already observed for similar compounds with the 'aryl-fluorene-aryl' frameworks. ${ }^{24} \mathbf{3}$ possesses a higher quantum yield, $c a$. $90 \%$ than that of $\mathbf{1}$. This result is in accordance with the fact that the indenofluorene molecule possesses a higher quantum yield than that of the fluorene or spirobifluorene molecule. ${ }^{26} 2$ presents again a drastically different behaviour compared to its analogues $\mathbf{1}$ and $\mathbf{3}$ as its quantum yield is of only $35 \%$, fully consistent with the fact that the fluorescence of 2 arises from intramolecular excimers. ${ }^{32,46,47}$ However, despite being smaller than those of $\mathbf{1}$ and $\mathbf{3}$, the quantum yield of $\mathbf{2}$ remains relatively high for an excimer-based emission. Thus, in the case of $\mathbf{2}$, due to the rigidity of the backbone, the "aryl-fluorene-aryl" chromophores are located

Table 1 Electronic properties of compounds 1, 2 and $\mathbf{3}$

\begin{tabular}{lllll}
\hline & $\mathrm{HOMO}^{a} / \mathrm{eV}$ & $\mathrm{LUMO}^{b} / \mathrm{eV}$ & $\Delta E^{\mathrm{opt} c} / \mathrm{eV}$ & Ref. \\
\hline 1 & -5.49 & -2.04 & 3.45 & 14 \\
2 & -5.33 & -1.94 & 3.39 & 14 \\
3 & -5.43 & -2.26 & 3.17 & This work
\end{tabular}

${ }^{a}$ Calculated from the onset oxidation potential $E_{\text {onset }}{ }^{\text {ox }}$ (HOMO $(\mathrm{eV})=-\left[E_{\text {onset }}^{\text {ox }}(v s\right.$. SCE $\left.)+4.4\right]$, based on an SCE energy level of 4.4 $\mathrm{eV}$ relative to the vacuum). ${ }^{b}$ Calculated from the HOMO energy level and the optical band gap. ${ }^{c}$ Optical band gap $\Delta E^{\mathrm{opt}}=h c / \lambda\left(\Delta E^{\mathrm{opt}}(\mathrm{eV})=\right.$ $1237.5 / \lambda$ in $\mathrm{nm}$ ) has been estimated from the liquid UV-vis spectra in THF ( $\lambda$ is the edge of the absorption spectrum). closely, in a favourable conformation, and require only a very slight spatial reorganization to form excimers. This close vicinity between the two "aryl-fluorene-aryl" chromophores probably leads to a decrease of any non-radiative decay processes and hence keeps the quantum yield at a reasonable value ( $c a .35 \%)$, hence promising for further OLED applications.

To conclude on the optical properties of these molecular systems, one can say that their fluorescences are drastically different and are mainly driven: in $\mathbf{1}$, by the "aryl/fluorene/aryl" moieties, in $\mathbf{2}$ by the excited dimer constituted of two face-to-face "aryl/fluorene/aryl" moieties and in $\mathbf{3}$ by the "aryl/indenofluorene/aryl" moiety. In addition, we noted for $\mathbf{2}$ very appealing properties for a fluorophore in which the fluorescence arises from excimer emission. Indeed, its quantum yield is in an acceptable range and its thin-film fluorescence spectrum is almost unchanged compared to its solution spectrum.

An important feature in OLED technology and particularly for blue light is related to the stability of the colour as a function of the temperature. ${ }^{48}$ Indeed, it is known that an OLED device can reach a temperature of $c a .86{ }^{\circ} \mathrm{C}$ and the stability of the emitted colour upon heating in air is hence of key importance. ${ }^{49}$

In order to determine the stability of the colour, spin-coated films of DSF-IFs 1-3 on quartz substrates were exposed to thermal stress conditions under ambient atmosphere (Fig. 3). Gradual heating of a spin-coated film of $\mathbf{1}$, in air, from room temperature to $200{ }^{\circ} \mathrm{C}(1 \mathrm{~h}$ for each stage and finally one day at $200{ }^{\circ} \mathrm{C}$ ), leads to a red-shift of around $6 \mathrm{~nm}$ and a broader spectrum. However, even after $24 \mathrm{~h}$ at $200{ }^{\circ} \mathrm{C}$ in the presence of air, no sign of low-energy emission band usually called Green Emission Band (GEB) was observed as it is usually the case for fluorene derivatives. ${ }^{48,50}$ For example, Lahti and co-workers have recently investigated the behaviour of fluorescent spectra as a function of the temperature for $E, E$-(2,7-bis(3,4,5trimethoxyphenylethenyl-9,9'-diethylfluorene)), a structurally related compound to $\mathbf{1}$. The authors have notably reported the existence of an important GEB $(\lambda=540 \mathrm{~nm})$ after heating a thin film at $200{ }^{\circ} \mathrm{C}$ in the presence of air. ${ }^{51}$ This GEB emission has been assigned to the presence of fluorenone moieties at the fluorene bridge due to the oxidation process. However, in the case of 1 possessing spiro aryl bridges (and not alkyl bridges), no oxidation degradation processes leading to a GEB is observed. The emission colour of $\mathbf{1}$ appears then to be highly stable upon heating in the presence of air. In the case of $\mathbf{3}$, gradual heating of a spin-coated film, in air, from room temperature to $160^{\circ} \mathrm{C}$ does not lead to any modification of the shape of the fluorescent spectra, highlighting the high colour stability. This feature has been assigned to the presence of two $t$-butyl-fluorene units on each side of the indenofluorenyl core leading to a steric protection and then avoiding any $\pi-\pi$ intermolecular interaction. ${ }^{12}$

The most striking feature here is again related to the compound 2. Thus, from room temperature to $160{ }^{\circ} \mathrm{C}$, the fluorescence spectrum of $\mathbf{2}$ remains perfectly stable with a main emission centred at $463 \mathrm{~nm}$ (no additional GEB and no broadening of the spectrum compared to the solution spectrum). This feature is remarkable since the fluorescence emission of $\mathbf{2}$ results from excimer emission. Interestingly, the heating at $200{ }^{\circ} \mathrm{C}$ is accompanied by a slight modification of the fluorescence spectrum which now presents a maximum at $453 \mathrm{~nm}$, surprisingly in accordance with that of its solution fluorescence spectrum. 

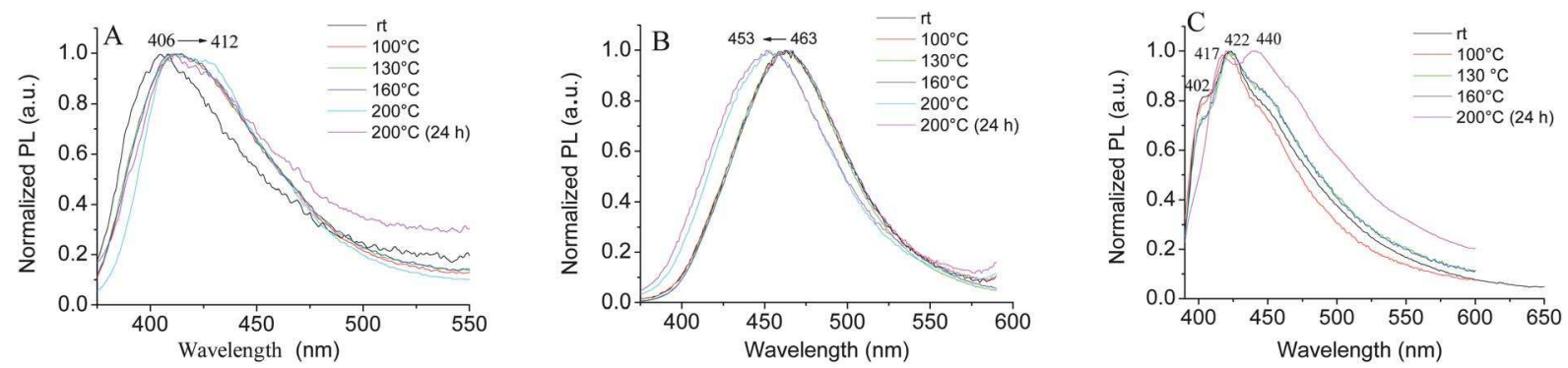

Fig. 3 Normalized fluorescence spectra of 1 (A), 2 (B) and 3 (C) in the solid state at various temperatures $\left(1 \mathrm{~h}\right.$ for each stage and one day at $200{ }^{\circ} \mathrm{C}$ ), $\lambda_{\mathrm{exc}}=300 \mathrm{~nm}\left(\mathbf{1}\right.$ and 2), $\lambda_{\mathrm{exc}}=317 \mathrm{~nm}$ (3); depositing solvent: 1,2-dichlorobenzene, $C=15 \mathrm{mg} \mathrm{mL}^{-1}\left(\mathbf{1}\right.$ and 2); THF; $C=10 \mathrm{mg} \mathrm{mL}{ }^{-1}(\mathbf{3})$.

Similar changes of the solid-state fluorescence spectrum with temperature are described in the literature for butadiene derivatives, ${ }^{3,52,53}$ but in these examples, the monomer-like or excimerlike fluorescence comes from specific "intermolecular packing" which may be modified with the temperature. In a "herringbone" arrangement, minimal electronic coupling between molecules leads to a monomer-like emission, whereas in a "brickstone" arrangement, molecular packing leads to excimer-like fluorescence. In the case of $\mathbf{2}$, as previously observed for spiroterfluorene face-to-face fluorophores ${ }^{16}$ heating of the films leads to a slight reorganization of the face-to-face "aryl-fluorene-aryl" moieties in the solid with less $\pi-\pi$ interactions and hence a blue shift of the emission band.

These studies showed the high colour stability upon heating of these three DSF-IFs derivatives. As the fluorescent emission of $\mathbf{2}$ arises from intramolecular excimer, the high stability of the deep blue colour appears even remarkable and to the best of our knowledge without any precedent.

\section{Small Molecule Organic Light-Emitting Diodes (SMOLEDs) using 1,2 and 3 as the emitting layer}

Several single-layer and double-layer OLEDs using $\mathbf{1}, \mathbf{2}$ and $\mathbf{3}$ as the emitting layer were fabricated and characterized (Fig. 4). The HOMO/LUMO levels of the three compounds have been then
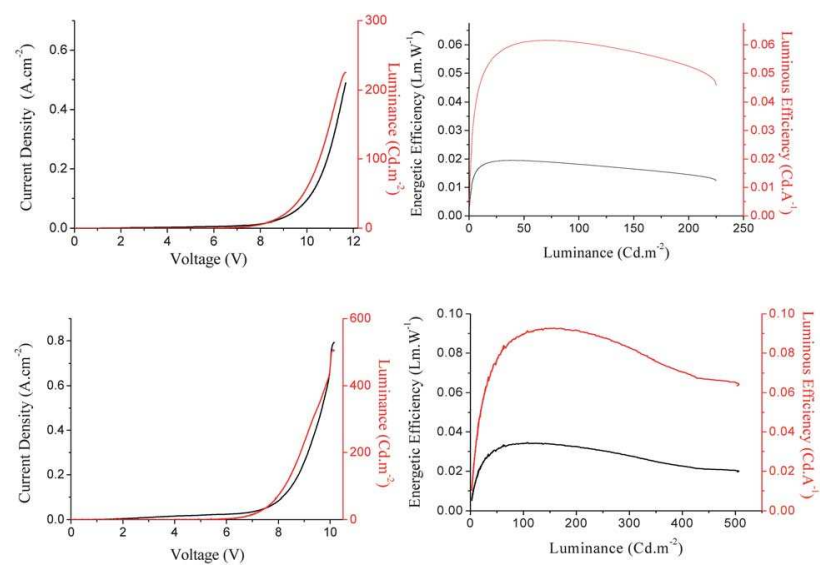

Fig. 4 Current density-voltage-luminance characteristics (left) and luminous/energetic efficiencies (right) of device B. Top: ITO/PEDOT/ NPB $(40 \mathrm{~nm}) / \mathbf{1}(50 \mathrm{~nm}) / \mathrm{Ca}$ device and bottom: ITO/PEDOT/NPB $(40 \mathrm{~nm}) / 2(45 \mathrm{~nm}) / \mathrm{Ca}$ device. evaluated from electrochemical data (see figures in the ESI $\dagger$ ) and optical data (Table 1).

We first decided to focus on single-layer devices to study the intrinsic properties of 1-3 when used as EML. Single-layer devices, ITO/PEDOT/EML/Ca (devices A), have been fabricated and characterized. In these devices, ITO/PEDOT is referred to as the anode, in which PEDOT (poly(3,4-ethylene dioxythiophene)) doped with PSS (poly(styrene sulfonate)) is the hole injecting layer and calcium is the cathode. These devices are considered as single-layer ones as PEDOT is not taken into account in the number of layers. The choice of the low work-function calcium cathode $(-2.9 \mathrm{eV})$ was evident in the light of the very high LUMO levels of all the compounds investigated (Table 1). The luminance of the device A using 1 as EML $(50 \mathrm{~nm})$ reaches around $52 \mathrm{Cd} \mathrm{m}^{-2}$ with luminous and energetic efficiencies of $3.1 \times 10^{-2} \mathrm{Cd} \mathrm{A}^{-1}$ and $1.1 \times 10^{-2} \mathrm{Lm} \mathrm{W}^{-1}$ respectively (see figures in the ESI $\dagger$ ). The turn-on voltage of the device, defined as the voltage for a luminance of $1 \mathrm{Cd} \mathrm{m}^{-2}$, is recorded around 7.2 V. For 3, the performance of the device A appears to be very similar to that discussed above for $\mathbf{1}$. Thus, the luminance of the device A using 3 as EML $\left(40 \mathrm{~nm}\right.$ ) reaches around $50 \mathrm{Cd} \mathrm{m}^{-2}$ (see figure in the ESI $\dagger$ ) with luminous and energetic efficiencies of $1.6 \times 10^{-2} \mathrm{Cd} \mathrm{A}^{-1}$ and $4 \times 10^{-3} \mathrm{Lm} \mathrm{W}^{-1}$ respectively (turn on voltage: $10.8 \mathrm{~V}$ ). The device A with 2 as EML ( $45 \mathrm{~nm}$ ) was finally investigated and a maximum luminance of $100 \mathrm{Cd} \mathrm{m}^{-2}$ with luminous and energetic efficiencies of $3.7 \times 10^{-2} \mathrm{Cd} \mathrm{A}^{-1}$ and $1.8 \times 10^{-2} \mathrm{Lm} \mathrm{W}^{-1}$ were obtained. This device not only exhibits the best performances among the investigated single-layer devices but also presents the lowest turn on voltage $(5 \mathrm{~V})$.

Three main information may be extracted from this dataset: (i) the three single-layer devices A display modest performances translating the difficulty in injecting charges in the three compounds. This feature was assigned to the wide HOMO/ LUMO gap of these materials coupled to their very high LUMO energy level (around $-2.0 /-2.2 \mathrm{eV}$, Table 1) and low HOMO energy level (around $-5.3 /-5.5 \mathrm{eV}$, Table 1), leading to a very high injection barrier for both electrons and holes. Even if the performances are modest, single-layer devices allow a perfect comparison of the intrinsic properties of each molecule and a clear definition of their potential for OLED applications. $\uparrow$ (ii) The molecules $\mathbf{1}$ and $\mathbf{3}$ which possess a similar HOMO/LUMO

I Very efficient single-layer OLEDs emitting a blue colour, key point for the future of OLED technology, requires to use very specific molecules with accurate molecular design such as donor-acceptor $\pi$-conjugated fluorescent dyes (see ref. 8-12). 
gap present nearly identical performances. (iii) The best results were obtained with $\mathbf{2}$ as EML. Indeed, despite $\mathbf{2}$ possessing a similar HOMO/LUMO gap compared to that of $\mathbf{1}$, the emission of $\mathbf{2}$ results from an "aryl-fluorene-aryl" dimer and then the electrogenerated exciton is delocalized over this dimer, leading to a red-shifted emission band (vide infra) and hence to enhanced performances.

In order to increase the performances, a thin layer of $\mathrm{NPB}\left(N, N^{\prime}-\right.$ $\operatorname{di}\left(1\right.$-naphthyl)- $N, N^{\prime}$-diphenyl-[1,1'-biphenyl]-4,4'-diamine) was deposited between the anode and the EML. The turn-on voltage of the ITO/PEDOT/NPB $(40 \mathrm{~nm}) / \mathbf{1}(50 \mathrm{~nm}) / \mathrm{Ca}$ (device B) appears at $c a$. $6.8 \mathrm{~V}$ with a luminance magnified by around 5 times compared to device $\mathrm{A}$, reaching $c a .230 \mathrm{Cd} \mathrm{m}^{-2}$ with efficiencies also magnified, $6.2 \times 10^{-2} \mathrm{Cd} \mathrm{A}^{-1}$ and $2 \times 10^{-3} \mathrm{Lm}$ $\mathrm{W}^{-1}$ (Fig. 4, top). Similarly, the ITO/PEDOT/NPB $(40 \mathrm{~nm}) / 2$ $(45 \mathrm{~nm}) / \mathrm{Ca}$ device $\mathrm{B}$ with 2 as EML also leads to a strong enhancement of the performances (Fig. 4, bottom). Indeed, the maximum luminance reaches around $510 \mathrm{Cd} \mathrm{m}^{-2}$ with a luminous efficiency of $c a$. $0.1 \mathrm{Cd} \mathrm{A}^{-1}$. The turn-on voltage of the double-layer device $\mathrm{B}(5.8 \mathrm{~V})$ is slightly higher than that of the single-layer device A due to the increase thickness of the organic layers. It is obvious that the performances of this excimer-based SMOLED are modest but: (i) the devices were not optimized, (ii) such intramolecular excimer based devices were without any precedent, (iii) the performances are magnified compared to a classical "aryl-fluorene-aryl" emitter such as $\mathbf{1}$, (iv) with a more accurate molecular design of the molecules (hole/electron transporting moieties) and/or of the devices ("band engineering" with hole/electron transporting/blocking layers, modification of the electrodes) the performances of the SMOLEDs will be surely and easily enhanced.

The last and crucial feature is finally related to the emission colour of these devices. The electro-optic properties of the devices $\mathrm{A}$ and $\mathrm{B}$ are presented below (Fig. 5). For 1, two important features were noted. First, the Electroluminescent (EL) spectra seem to be dependent on the nature of the device. Indeed, the device A presents an EL spectrum with a blue emission recorded at $432 \mathrm{~nm}$ (Fig. 5A, red line) red shifted by 18 $\mathrm{nm}$ compared to its thermally evaporated thin film, $\lambda=414 \mathrm{~nm}$ (Fig. 5A, black line). The device B also presents a red-shift of its EL spectrum, nevertheless more pronounced with a maximum recorded at $448 \mathrm{~nm}$ (Fig. 5A, blue line). The second important feature is related to the shape of the EL spectra which appears to be not only larger than the PL spectrum but also with an additional GEB recorded at $c a$. $540 \mathrm{~nm}$. The origin of such contribution at low energy has been extensively studied for the last decade as it remains one important problem in blue OLED technology. ${ }^{48,50,54,55}$ It is widely agreed nowadays that the GEBs appearing in poly or oligo(dialkyl)fluorene arise from ketodefects in the form of fluorenone moieties. ${ }^{50}$ Similarly, GEBs have also been observed in structurally related poly- $p$-phenylenes such as poly(alkylindenofluorene) or ladder-type poly or oligo(alkylpentaphenylene). ${ }^{48,55-59}$ However, in the case of 1 , the bridges are protected by a spirofluorene unit, not sensitive to oxidation degradation processes ${ }^{55,60}$ and hence the oxidation of the bridges leading to keto-defects appears to be impossible. In addition, we have also shown above that even annealing in the presence of oxygen, the fluorescent emission spectra do not possess any GEB (Fig. 3A). Thus, it is difficult to assign the GEB observed in the EL spectra of 1 to intermolecular $\pi-\pi$ interactions leading to excimer emissions. We believe that this GEB may arise from interactions with the electrodes ${ }^{55,57}$ and/or exciplex emissions at the organic/organic interface, ${ }^{61,62}$ as previously described. Indeed, Ca-EML and/or PEDOT/PSS-EML interactions at the interface between the EML and the electrode have been previously suggested for similar extended $\pi$-conjugated backbones. ${ }^{55,57}$ The chromatic coordinates of the devices A and B with 1 as EML are $(0.24 ; 0.24) /(0.25 ; 0.27)$ respectively and correspond to a light blue colour (see the CIE diagram in the ESI $\dagger$ ).

In the case of 3, the device A presents an EL spectrum with a maximum recorded at $c a .452 \mathrm{~nm}$ and a long wavelength tail until $800 \mathrm{~nm}$, whereas the device $B$ presents a maximum red shifted by $38 \mathrm{~nm}\left(\lambda_{\max }=490 \mathrm{~nm}\right)$ and an even larger long wavelength tail with a shoulder at $700 \mathrm{~nm}$, Fig. 5C. This large band (with its shoulder at $700 \mathrm{~nm}$ ) found in device B can be tentatively assigned to exciplex emission due to the interactions at the organic/organic interface. ${ }^{61,62}$ This is confirmed by the fact that both devices possess EL spectra strongly red-shifted compared to the fluorescent spectrum of 3 (Fig. 5C, black line).

Finally for 2, the EL spectrum of the device A exhibits a nice structureless band with a maximum at $447 \mathrm{~nm}$ (Fig. 5B, red line), whereas the device $\mathrm{B}$ displays a maximum slightly red-shifted at $462 \mathrm{~nm}$ (Fig. 5B, blue line). These two EL spectra, opposite to those of $\mathbf{1}$ and $\mathbf{3}$, are in accordance with the thermally evaporated PL spectrum of $\mathbf{2}$ (Fig. 5B, black line) clearly signifying that the fluorescent emission of the device arises, without any doubt, from electrogenerated intramolecular excimer. A slight blue shift is nevertheless noted between the EL spectrum of device A $\left(\lambda_{\max }=447 \mathrm{~nm}\right)$ and the PL spectrum of $2\left(\lambda_{\max }=461 \mathrm{~nm}\right)$. Such
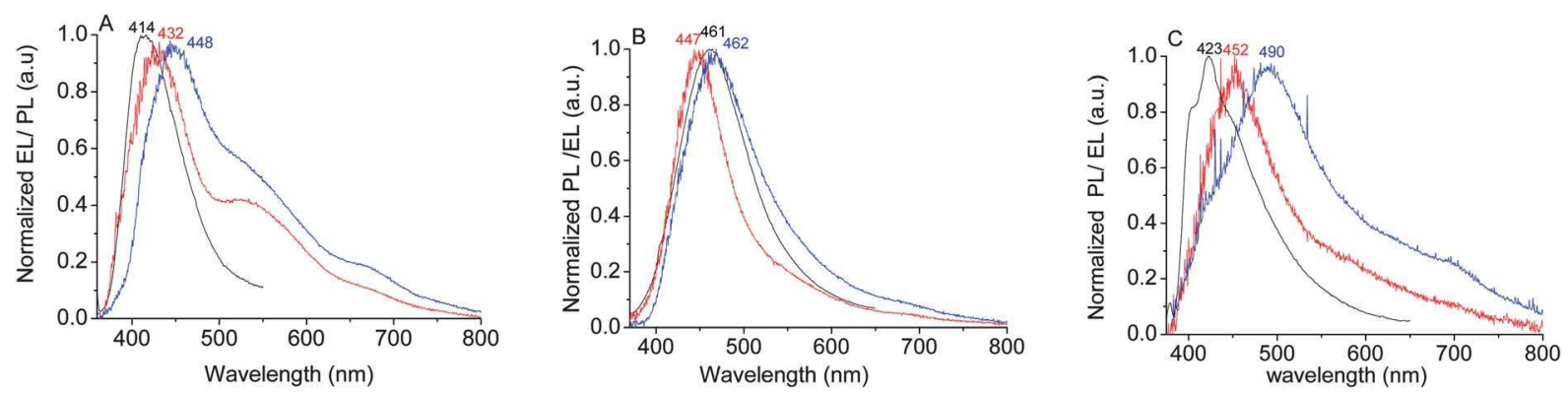

Fig. 5 Electroluminescent spectra using 1 (A), 2 (B) and 3 (C), as EML: device A (red), device B (blue) and thermally evaporated ( 260 ${ }^{\circ} \mathrm{C}$ for $\mathbf{1}$ and $\mathbf{2}$ ) and spin-coated (3) thin-film PL spectra (black). 
a feature has been also recently reported by Müllen and coworkers for dendrimer based blue OLEDs. ${ }^{63}$ This point needs to be nevertheless elucidated in further studies. In addition, no sign of intermolecular excimer leading to undesired GEB was detected, clearly signifying that the molecules of $\mathbf{2}$ in the thin-film are isolated enough to avoid any $\pi-\pi$ intermolecular interaction. This site isolation is a key feature to ensure an efficient fluorescence and highlights the potential of the present molecular design for blue OLED applications. In addition, no band arising from keto-defects or from exciplex formation was detected as it was the case for $\mathbf{1}$ and $\mathbf{3}$. The chromatic coordinates of the devices A and B with 2 as EML are almost identical $(0.19 ; 0.19)$ and $(0.19$; 0.18 ) respectively, and correspond to a deep blue colour (see the CIE diagram in the ESI $\dagger$ ). In summary, the intramolecular excimer based-OLEDs not only display a stable deep blue colour with no trace of GEB due to "site isolation" of the molecules in the film but also present magnified performances compared to those of other devices with structurally related compounds ( $\mathbf{1}$ and 3). Generating intramolecular excimers emission through the highly rigid (2,1-a)-DSF-IF molecular platform appears hence as an interesting new strategy to design electroluminescent devices. Indeed, this strategy allows obtaining a deep blue emission (PL and EL) centred at $460 \mathrm{~nm}$ with a short $\pi$-conjugated 'aryl-fluorene-aryl' fragment, whereas this emission wavelength is almost impossible to obtain with structurally related oligo 'aryl-fluorene-aryl' derivatives even with a large number of aryl substituents. $^{24}$

\section{Conclusion}

DSF-IF 2 has been successfully used as an emitting layer in a SMOLED leading to a stable deep blue emission arising from electrogenerated intramolecular excimers with better performances compared to those of structurally related compounds. This is to the best of our knowledge the first rational and comparative study describing the use of intramolecular excimers arising from organic molecules as blue light source in a SMOLED. Thus, due to the geometry of the rigid (2,1-a)-DSFIF platform, the 'aryl/fluorene/aryl' dimer is preformed in the ground state favouring the facile and easily controllable formation of excimers in the excited state and leading to a deep blue fluorescent emission $(\lambda=460 \mathrm{~nm})$ through strong $\pi-\pi$ intramolecular interactions. This emission wavelength is almost impossible to obtain with the direct connection of simple aryl units to a fluorene core ${ }^{24}$ and highlights the interest of the present strategy. The simple and non-optimized double-layer device using 2 as EML displays a deep blue colour (CIE coordinates: $0.19 ; 0.18$ ) exhibiting a luminance of $510 \mathrm{Cd} \mathrm{m}^{-2}$ with a luminous efficiency of $c a .0 .1 \mathrm{Cd} \mathrm{A}^{-1}$. More sophisticated SMOLED designs, such as the use of carrier blocking layers, will easily allow the device performances to be significantly optimized. In addition, more experiments are nevertheless necessary in order to perfectly understand the physical and electronic properties of these intramolecular excimer based devices and to take full advantage of the favourable properties of this new molecular design. Regarding the importance of fluorene derivatives in organic electronics and the number of molecular platforms (pyrene, naphthalene, etc. ${ }^{36}$ which have been used to induce intramolecular excimer emission, the present structure/property relationship study may open new avenues in the design of efficient blue OLEDs.

\section{Experimental section}

\section{Synthesis}

Commercially available reagents and solvents were used without further purification other than those detailed below. THF was distilled from sodium/benzophenone prior to use. Toluene was distilled from sodium prior to use. Light petroleum refers to the fraction with bp $40-60{ }^{\circ} \mathrm{C}$. Reactions were stirred magnetically, unless otherwise indicated. Analytical thin layer chromatography was carried out using aluminium backed plates coated with Merck Kieselgel 60 GF254 and visualized under UV light (at 254 and $360 \mathrm{~nm}$ ). Chromatography was carried out using silica 60A CC 40-63 $\mu \mathrm{m}$ (SDS). ${ }^{1} \mathrm{H}$ and ${ }^{13} \mathrm{C}$ NMR spectra were recorded using Bruker $300 \mathrm{MHz}$ instruments ( ${ }^{1} \mathrm{H}$ frequency, corresponding ${ }^{13} \mathrm{C}$ frequency: $75 \mathrm{MHz}$ ); chemical shifts were recorded in ppm and $J$ values in $\mathrm{Hz}$. In the ${ }^{13} \mathrm{C}$ NMR spectra, signals corresponding to $\mathrm{CH}, \mathrm{CH}_{2}$ or Me groups, assigned from DEPT, are noted; all others are $\mathrm{C}$. The residual signals for the NMR solvent $\mathrm{CD}_{2} \mathrm{Cl}_{2}$ are $5.32 \mathrm{ppm}$ for the proton and $53.80 \mathrm{ppm}$ for the carbon. The following abbreviations have been used for the NMR assignment: s for singlet, $\mathrm{d}$ for doublet, $\mathrm{t}$ for triplet and $\mathrm{m}$ for multiplet. High resolution mass spectra were recorded at the Centre Régional de Mesures Physiques de l'Ouest (Rennes). The synthesis and the full characterization of 1,2 and $\operatorname{DSF}(t-\mathbf{B u})_{4}-\mathbf{I F}(\mathbf{B r})_{2}$ may be found in our previous works. ${ }^{12,21}$

\section{Spectroscopic studies}

UV-visible spectra were recorded using a UV-Visible spectrophotometer Shimadzu UV-1605. The optical band gap was calculated from the absorption edge of the UV-vis absorption spectrum using the formula $\Delta E^{\text {opt }}(\mathrm{eV})=h c / \lambda, \lambda$ being the absorption edge (in metres). With $h=6.6 \times 10^{-34} \mathrm{~J} \mathrm{~s}(1 \mathrm{eV}=$ $1.6 \times 10^{-19} \mathrm{~J}$ ) and $c=3.0 \times 10^{8} \mathrm{~m} \mathrm{~s}^{-1}$, this equation may be simplified as: $\Delta E^{\text {opt }}(\mathrm{eV})=1237.5 / \lambda$ (in $\mathrm{nm}$ ). Photoluminescence spectra were recorded with a PTI spectrofluorimeter (PTI-814 PDS, MD 5020, LPS 220B) using a xenon lamp. Quantum yields in solution $\left(\phi_{\text {sol }}\right)$ were calculated relative to quinine sulfate ( $\phi_{\text {sol }}=0.546$ in $\mathrm{H}_{2} \mathrm{SO}_{4} 1 \mathrm{~N}$ ) using standard procedures. $\phi_{\text {sol }}$ was determined according to the following eqn (1):

$$
\phi_{\mathrm{sol}}=\phi_{\text {ref }} \times 100 \times \frac{\left(T_{\mathrm{s}} \times A_{\mathrm{r}}\right)}{\left(T_{\mathrm{r}} \times A_{\mathrm{s}}\right)}\left(\frac{n_{\mathrm{s}}}{n_{\mathrm{r}}}\right)^{2}
$$

where subscripts $\mathrm{s}$ and $\mathrm{r}$ refer respectively to the sample and reference. The integrated area of the emission peak in arbitrary units is given as $T, n$ is the refracting index of the solvent $\left(n_{\mathrm{s}}=\right.$ 1.4072 for THF) and $A$ is the absorbance $(A<0.1)$. IR spectra were recorded on a Bruker Vertex 70 using a diamond crystal MIRacle ATR (Pike).

\section{Electrochemical studies}

All electrochemical experiments were performed under an argon atmosphere, using a Pt disk electrode (diameter $1 \mathrm{~mm}$ ), the counter electrode was a vitreous carbon rod and the reference 
electrode was a silver wire in a $0.1 \mathrm{M} \mathrm{AgNO}_{3}$ solution in $\mathrm{CH}_{3} \mathrm{CN}$. Ferrocene was added to the electrolyte solution at the end of a series of experiments. The ferrocene/ferrocenium $\left(\mathrm{Fc} / \mathrm{Fc}^{+}\right)$ couple served as the internal standard. The three electrode cell was connected to a PAR Model 273 potentiostat/galvanostat (PAR, EG\&G, USA) monitored with the ECHEM Software. Activated $\mathrm{Al}_{2} \mathrm{O}_{3}$ was added to the electrolytic solution to remove excess moisture. All potentials are referred to the SCE electrode that was calibrated at $-0.405 \mathrm{~V} v s$. $\mathrm{Fc} / \mathrm{Fc}^{+}$system.

\section{OLED fabrication and testing}

OLEDs were fabricated using the following procedure. Indiumtin oxide (ITO) substrates on glass from Merck underwent a solvent ultrasonic cleaning using acetone, ethanol and isopropanol followed by a 15 min UV-ozone treatment. A layer of poly(3,4-ethylene dioxythiophene) doped with poly(styrene sulfonate) (PEDOT/PSS from Aldrich) was then deposited onto ITO by spin-coating at $6000 \mathrm{rpm}$, from a $3 \mathrm{wt} \%$ water dispersion to form a $40 \mathrm{~nm}$ thick layer. PEDOT/PSS was subsequently annealed at $120{ }^{\circ} \mathrm{C}$ under vacuum for 40 minutes. This layer improves hole injection from the ITO to the HOMO level of the organic material and increases the performances and the lifetime of the device. Then a layer of $\mathbf{1}, \mathbf{2}$ or $\mathbf{3}$ or a NPB $\left(N, N^{\prime}-\operatorname{di}(1-\right.$ naphthyl)- $N, N^{\prime}$-diphenyl-[1, $1^{\prime}$-biphenyl]-4,4'-diamine) layer followed by a layer of $\mathbf{1}, \mathbf{2}$ or $\mathbf{3}$ were thermally evaporated under vacuum ( $\mathrm{ca}$. $10^{-6}$ mbar). The layer thickness was monitored in situ during the evaporation via a piezoelectric quartz. Calcium cathodes $(200 \mathrm{~nm})$ were evaporated through a shadow mask. The OLEDs were then stored and characterized under inert atmosphere in a nitrogen glove box $\left(\left[\mathrm{O}_{2}\right]\right.$ and $\left.\left[\mathrm{H}_{2} \mathrm{O}\right]<1 \mathrm{ppm}\right)$. Current-voltage-luminance $(I-V-L)$ curves were recorded using a Keithley 4200 SCS. Light emission was collected using a calibrated photodiode. Electroluminescence spectra were measured with a CCD spectrometer (Ocean Optics HR 2000).

3: 3,4,5-Trimethoxyphenyl boronic acid (140 $\mathrm{mg}, 0.65 \mathrm{mmol})$, $\mathbf{D S F}(\boldsymbol{t} \text {-Bu })_{\mathbf{4}} \mathbf{- I F}(\mathbf{B r})_{\mathbf{2}}(250 \mathrm{mg}, 0.27 \mathrm{mmol}), \mathrm{Pd}_{2} \mathrm{dba}_{3}$ (24 mg, 0.03 mmol) and tri-tert-butyl phosphine $(20 \mu \mathrm{L}, 0.08 \mathrm{mmol})$ were dissolved in toluene $(250 \mathrm{~mL})$ under an argon atmosphere. $\mathrm{K}_{2} \mathrm{CO}_{3}$ (100 mg, $0.68 \mathrm{mmol}$ ) dissolved in water was added and the mixture was stirred at $100{ }^{\circ} \mathrm{C}$ for 15 hours and, after cooling, poured into a saturated ammonium chloride solution. Ethyl acetate was added, the different layers separated and the residual aqueous solution was extracted with dichloromethane. The combined extracts were dried $\left(\mathrm{MgSO}_{4}\right)$, evaporated in vacuo and purified by column chromatography on silica gel, eluting with light petroleum-ethyl acetate $8: 2$. The title compound 3 $(165 \mathrm{mg}, 55 \%)$ was afforded as a colorless solid. Mp (hexane) $>$ $300{ }^{\circ} \mathrm{C} ;{ }^{1} \mathrm{H}$ NMR $\left(300 \mathrm{MHz}, \mathrm{CD}_{2} \mathrm{Cl}_{2}\right) \delta 7.83(4 \mathrm{H}, \mathrm{dd}, J=8.1 \mathrm{~Hz}$, $J=0.6 \mathrm{~Hz}, \mathrm{ArH}), 7.65(2 \mathrm{H}, \mathrm{d}, J=8.1 \mathrm{~Hz}, \mathrm{ArH}), 7.51-7.44(6 \mathrm{H}$, m, ArH), 7.19 (2H, s, ArH), 6.85 (2H, d, $J=1.3 \mathrm{~Hz}, \mathrm{ArH}), 6.79$ $(4 \mathrm{H}, \mathrm{d}, J=1.4 \mathrm{~Hz}, \mathrm{ArH}), 6.56(4 \mathrm{H}, \mathrm{s}, \mathrm{ArH}), 3.75(12 \mathrm{H}, \mathrm{s}, \mathrm{Me})$, $3.71(6 \mathrm{H}, \mathrm{s}, \mathrm{Me}), 1.17(36 \mathrm{H}, \mathrm{s}, \mathrm{Me}) ;{ }^{13} \mathrm{C} \mathrm{NMR}\left(75 \mathrm{MHz}, \mathrm{CD}_{2} \mathrm{Cl}_{2}\right)$ $\delta 153.8(\mathrm{C}), 151.4(\mathrm{C}), 150.9$ (C), 150.5 (C), 149.4 (C), 141.7 (C), $141.5(\mathrm{C}), 141.0(\mathrm{C}), 139.8(\mathrm{C}), 138.1(\mathrm{C}), 137.2(\mathrm{C}), 127.0(\mathrm{CH})$, $125.4(\mathrm{CH}), 122.5(\mathrm{CH}), 121.0(\mathrm{CH}), 120.6(\mathrm{CH}), 119.7(\mathrm{CH})$, $115.7(\mathrm{CH}), 104.8(\mathrm{CH}), 66.7\left(\mathrm{C}_{\text {spiro }}\right), 60.8(\mathrm{OMe}), 56.5(\mathrm{OMe})$, 35.1 (CMe), $31.6(\mathrm{Me})$; HRMS (ESI ${ }^{+}, \mathrm{CH}_{2} \mathrm{Cl}_{2}: \mathrm{CH}_{3} \mathrm{OH} 8: 2$ ): (found: $[\mathrm{M}+\mathrm{Na}]^{+}, 1133.5690 ; \mathrm{C}_{78} \mathrm{H}_{78} \mathrm{O}_{6} \mathrm{Na}$ required 1133.5691);
IR $\left(\mathrm{ATR}, \mathrm{cm}^{-1}\right) \nu=3066,3031,2953,2902,2867,2832,1585$, 1511, 1494, 1459, 1427, 1402, 1361, 1342, 1243, 1173, 1126.

\section{Acknowledgements}

DT thanks the Région Bretagne for a studentship. MR thanks the Région Bretagne and l'Agence de l'Environnement et de la Maîtrise de l'Energie (ADEME) for a studentship. The OLED fabrication/characterization has been performed at the ENSCBP (IMS/UMR CNRS 5218-Bordeaux) and we wish to highly thank Sokha Khiev and Dr Laurence Vignau for their help and fruitful discussions.

\section{References}

1 M. M. Ling and Z. Bao, Chem. Mater., 2004, 16, 4824.

2 V. Coropceanu, J. Cornil, D. A. da Silva Filho, Y. Olivier, R. Silbey and J. L. Brédas, Chem. Rev., 2007, 107, 926.

3 S. Varghese and S. Das, J. Phys. Chem. Lett., 2011, 2, 863.

4 J. E. Anthony, Chem. Rev., 2006, 106, 5028.

5 M. Mazzeo, V. Vitale, F. Della Sala, M. Anni, G. Barbarella, L. Favaretto, G. Sotgiu and G. Gigli, Adv. Mater., 2005, 17, 34.

6 Y. Liu, M. Nishiura, Y. Wang and Z. Hou, J. Am. Chem. Soc., 2006, 128, 5592.

7 S. Tao, Y. Zhou, C.-S. Lee, S.-T. Lee, D. Huang and X. Zhang, J. Mater. Chem., 2008, 18, 3981

8 L. Duan, J. Qiao, Y. Sun and Y. Qiu, Adv. Mater., 2011, 23, 1137.

9 A. L. Fischer, K. E. Linton, K. T. Kamtekar, C. Pearson, M. R. Bryce and M. C. Petty, Chem. Mater., 2011, 23, 1640.

10 H. Jiang, Macromol. Rapid Commun., 2010, 31, 2007.

11 J. Huang, J.-H. Su, X. Li, M.-K. Lam, K.-M. Fung, H.-H. Fan, K.-W. Cheah, C. H. Chen and H. Tian, J. Mater. Chem., 2011, 21, 2957.

12 D. Thirion, J. Rault-Berthelot, L. Vignau and C. Poriel, Org. Lett., 2011, 13, 4418.

13 N. Cocherel, C. Poriel, J. Rault-Berthelot, F. Barrière, N. Audebrand, A. M. Z. Slawin and L. Vignau, Chem.-Eur. J., 2008, 14, 11328.

14 D. Thirion, C. Poriel, R. Métivier, J. Rault-Berthelot, F. Barrière and O. Jeannin, Chem.-Eur. J., 2011, 17, 10272.

15 D. Thirion, C. Poriel, F. Barrière, R. Métivier, O. Jeannin and J. Rault-Berthelot, Org. Lett., 2009, 11, 4794.

16 C. Poriel, J. Rault-Berthelot, D. Thirion, F. Barrière and L. Vignau, Chem.-Eur. J., 2011, 50, 14031.

17 G. Zhang, H.-H. Chou, X. Jiang, P. Sun, C.-H. Cheng, Y. Ooyama and Y. Harima, Org. Electron., 2010, 11, 632.

18 B. W. D'Andrade, J. Brooks, V. Adamovich, M. E. Thompson and S. R. Forrest, Adv. Mater., 2002, 14, 1032.

19 E. L. Williams, K. Haavisto, J. Li and G. E. Jabbour, Adv. Mater., 2007, 19, 197.

20 V. Adamovich, J. Brooks, A. Tamayo, A. M. Alexander, P. I. Djurovich, B. W. D'Andrade, C. Adachi, S. R. Forrest and M. E. Thompson, New J. Chem., 2002, 26, 1171.

21 C. Poriel, F. Barrière, D. Thirion and J. Rault-Berthelot, Chem.-Eur. J., 2009, 15, 13304.

22 J. Salbeck, N. Yu, J. Bauer, F. Weissörtel and H. Bestgen, Synth. Met., 1997, 91, 209.

23 J. Salbeck, F. Weissörtel and J. Bauer, Macromol. Symp., 1997, 125, 121.

24 T. P. I. Saragi, T. Spehr, A. Siebert, T. Fuhrmann-Lieker and J. Salbeck, Chem. Rev., 2007, 107, 1011.

25 D. Thirion, C. Poriel, J. Rault-Berthelot, F. Barrière and O. Jeannin, Chem.-Eur. J., 2010, 16, 13646.

26 C. Poriel, J.-J. Liang, J. Rault-Berthelot, F. Barrière, N. Cocherel, A. M. Z. Slawin, D. Horhant, M. Virboul, G. Alcaraz, N. Audebrand, L. Vignau, N. Huby, G. Wantz and L. Hirsch, Chem.-Eur. J., 2007, 13, 10055.

27 S. Merlet, M. Birau and Z. Y. Wang, Org. Lett., 2002, 4, 2157.

28 T. Hadizad, J. Zhang, D. Yan, Z. Y. Wang, J. P. M. Serbena, M. S. Meruvia and I. A. Hümmelgen, J. Mater. Sci.: Mater. Electron., 2007, 18, 903.

29 T. Fuhrmann and J. Salbeck, Adv. Photochem., 2002, 27, 83. 
30 T. Spehr, R. Pudzich, P. Fuhrmann and J. Salbeck, Org. Electron., $2003,4,61$.

31 H. Etori, X. L. Jin, T. Yasuda, S. Mataka and T. Tsutsui, Synth. Met., 2006, 156, 1090.

32 B. S. Nehls, F. Galbrecht, A. Bilge, D. J. Brauer, C. W. Lehmann, U. Scherf and T. Farrell, Org. Biomol. Chem., 2005, 3, 3213.

33 R. Nandy and S. Sankararaman, Org. Biomol. Chem., 2010, 8, 2260.

34 T. Nakano and T. Yade, J. Am. Chem. Soc., 2003, 125, 15474.

35 H. Benten, H. Ohkita, S. Ito, M. Yamamoto, N. Sakumoto, K. Hori, Y. Tohda, K. Tani, Y. Nakamura and J. Nishimura, J. Phys. Chem. $B, 2005,109,19681$.

36 F. M. Winnik, Chem. Rev., 1993, 93, 587.

37 D. Mansell, N. Rattray, L. L. Etchells, C. H. Schwalbe, A. J. Blake, E. V. Bichenkova, R. A. Bryce, C. J. Barker, A. Diaz, C. Kremer and S. Freeman, Chem. Commun., 2008, 5161.

38 F. D. Lewis and T. L. Kurth, Can. J. Chem., 2003, 81, 770.

39 H. S. Jung, M. Park, D. Y. Han, E. Kim, C. Lee, S. Ham and J. S. Kim, Org. Lett., 2009, 11, 3378.

40 A. Qin, C. K. W. Jim, Y. Tang, J. W. Y. Lam, J. Liu, F. Mahtab, P. Gao and B. Z. Tang, J. Phys. Chem. B, 2008, 112, 9281.

41 J.-F. Wang, J.-K. Feng, A.-M. Ren and L. Yang, Chin. J. Chem., 2005, 23, 1618.

42 M. Belletête, M. Ranger, S. Beaupré, M. Leclerc and G. Durocher, Chem. Phys. Lett., 2000, 316, 101.

43 G. Heimel, M. Daghofer, J. Gierschner, E. J. W. List, A. C. Grimsdale, K. Müllen, D. Beljonne, J. L. Brédas and E. Zojer, J. Chem. Phys., 2005, 122, 054501.

44 Y. Wu, J. Zhang and Z. Bo, Org. Lett., 2007, 9, 4435.

45 A. Iida and S. Yamaguchi, Chem. Commun., 2009, 3002.

46 K. R. J. Thomas, J. T. Lin, C.-M. Tsai and H.-C. Lin, Tetrahedron, 2006, 62, 3517.

47 D. L. Horrocks and W. G. Brown, Chem. Phys. Lett., 1970, 5, 117.
48 A. C. Grimsdale and K. Müllen, Macromol. Rapid Commun., 2007, 28, 1676.

49 X. Zhou, J. He, L. S. Liao, M. Lu, X. M. Ding, X. Y. Hou, X. M. Zhang, X. Q. He and S.-T. Lee, Adv. Mater., 2000, 12, 265.

50 K. L. Chan, M. Sims, S. I. Pascu, M. Ariu, A. B. Holmes and D. D. C. Bradley, Adv. Funct. Mater., 2009, 19, 2147.

51 H. P. Rathnayake, A. Cirpan, P. M. Lahti and F. E. Karasz, Chem. Mater., 2006, 18, 560.

52 N. S. S. Kumar, S. Varghese, N. P. Rath and S. Das, J. Phys. Chem. C, 2008, 112, 8429 .

53 R. Davis, N. S. S. Kumar, S. Abraham, C. H. Suresh, N. P. Rath, N. Tamaoki and S. Das, J. Phys. Chem. C, 2008, 112, 2137.

54 A. C. Grimsdale, Curr. Org. Chem., 2010, 14, 2196.

55 C. Poriel, N. Cocherel, J. Rault-Berthelot, L. Vignau and O. Jeannin, Chem.-Eur. J., 2011, 17, 12631.

56 J. Jacob, S. Sax, M. Gaal, E. J. W. List, A. C. Grimsdale and K. Müllen, Macromolecules, 2005, 38, 9933.

57 A. K. Mishra, M. Graf, F. Grasse, J. Jacob, E. J. W. List and K. Müllen, Chem. Mater., 2006, 18, 2879.

58 L. Romaner, G. Heimel, H. Wiesenhofer, P. Scandiucci de Freitas, U. Scherf, J. L. Bredas, E. Zojer and E. J. W. List, Chem. Mater., 2004, 16, 4667.

59 C. E. Finlayson, J.-S. Kim, M. Liddell, R. H. Friend, S.-H. Jung, A. C. Grimsdale and K. Müllen, J. Chem. Phys., 2008, 128, 044703.

60 N. Cocherel, C. Poriel, L. Vignau, J.-F. Bergamini and J. RaultBerthelot, Org. Lett., 2010, 12, 452.

61 K. Itano, H. Ogawa and Y. Shirota, Appl. Phys. Lett., 1998, 72, 636.

62 J. Feng, F. Li, W. Gao, S. Liu, Y. Liu and Y. Wang, Appl. Phys. Lett., $2001,78,3947$.

63 T. Qin, G. Zhou, H. Scheiber, R. E. Bauer, M. Baumgarten, C. E. Anson, E. J. W. List and K. Müllen, Angew. Chem., Int. Ed., $2008,47,8292$. 